\title{
Measuring the correlation between neighborhood models and crime rates and sense of security. \\ A case study of four neighborhoods adjacent to criminal focal points in Cairo-Egypt.
}

\section{Islam Ghonimi Ibrahim , Islam Salah Eldin Shahata}

\section{Abstract}

The high concentration of low education level, low socio-economic level and high poverty level inside urban fabric creates criminal focal points that become a key factor associated with the increase of crime rates and the reduction of sense of security. These criminal points impose a great risk to their adjacent neighborhoods; some adjacent neighborhoods inherently facilitate crime opportunities, whereas others do not. Based on case study of four crimeaffected neighborhoods, this research provides an understanding the correlation between specific neighborhoods features and both recorded crime rates and deduced resident's sense of safety and security.

The results suggest two conclusions; the first regarding residents sense of safety, it is deduced that neither traditional neighborhood with extremely densification, mixed use on building level, and grid with high intersection points, nor the modern neighborhood with extremely low density, separate use, and tree street network pattern, can increase sense of safety. The second regarding crime rates, it is recorded that traditional districts can mitigate the potential risk of criminal focal pints and reduce crime rates compared to modern districts.

\section{Keywords}

Crime opportunities, crime rates, crime prevention through environmental design (CPTED), fear of crime, sense of safety and security, neighborhood urban patterns.

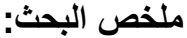

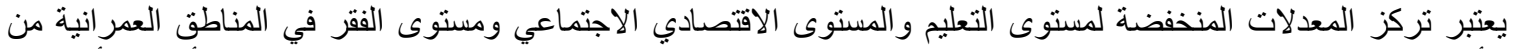

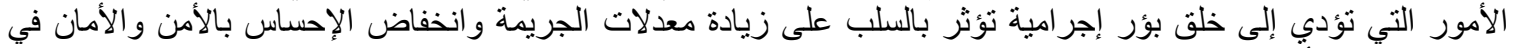

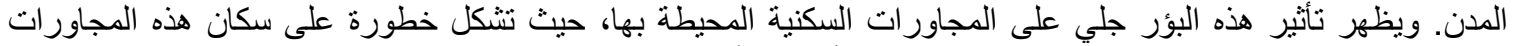

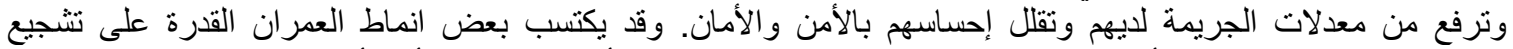

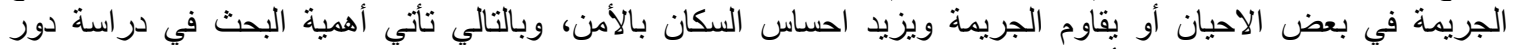

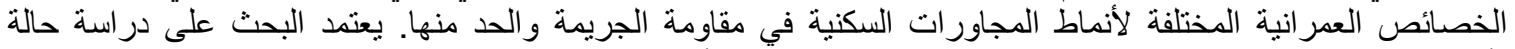

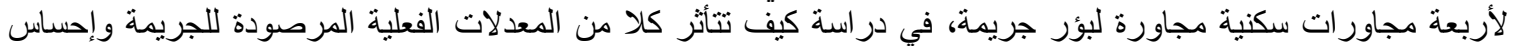

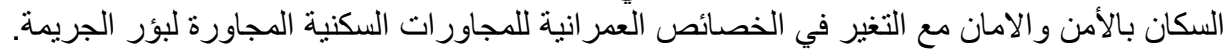

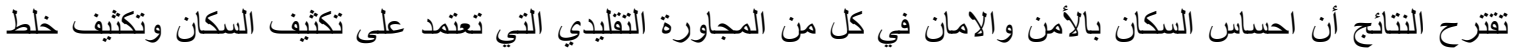

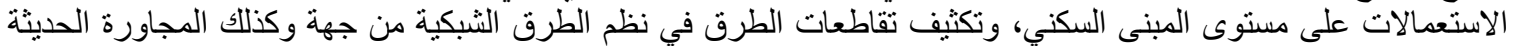

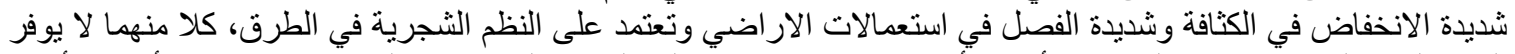

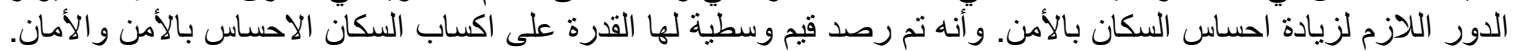

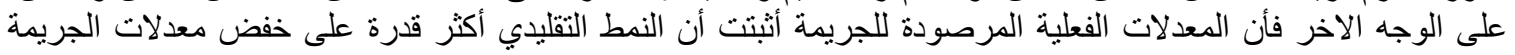

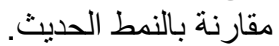

الكلمات المفتاحية: فرص الجرية بالفيمة، معدلات الجريمة، منع الجريمة بواسطة التصميم البيئي، الخوف من الجريمة، الاحساس بالأمن و الامان، انماط المجاورة فرل السكنية. 


\section{Introduction}

The concentration of low education, low socio-economic level and high poverty in residential areas are key factors associated with emergence of criminal focal points that are key factors associated with the increase of crime rates and the reduction of sense of security. The adjacency of such focal points to residential areas becomes a big problem for adjacent communities' residents. The high crime rates in recent days, and the low sense of security and safety in residential areas; makes the study of the factors that can reduce crime rates and increases resident's sense of security in the main concern of this research; a study to define the relation exists between neighborhood urban patterns and crime prevention.

Some neighborhoods encourage crime opportunities, whereas others do not. An understanding of the reason that some neighborhoods provide more security defensible behavior against crime than others is important to improve crime prevention. This study examines whether neighborhood design affects the degree to which it can face and prevent crime opportunities and the degree it can provide sense of safety and security to its residents.

Traditional neighborhood types are mixed use and pedestrian oriented. Residents have daily services within walking distance. Theoretically, these types are most likely to reduce crime opportunities. They encourage walking; enabling residents to perform daily activities without the use of a car. Their pedestrians are not forced to compete with cars along busy highways. They are expected to enhance social capital because they enable residents to interact intentional or accidental. They can encourage a sense of trust and a sense of connection between people. To many residents, such contacts breed a sense of familiarity. They create a web of public respect and trust, and a resource in time of personal or neighborhood need (Houghton 2006; Berube 2005; Jacobs 1961; Lofland, 1973; Berube 2005).

On the Contrary, modern neighborhood types contain only houses and car oriented. Daily needs are not met in the neighborhood, so residents have to travel by car to find services. Theoretically, they are most likely to increase crime rates. They do little to enable social interaction. Social interaction is more likely to occur by invitation, not by chance encounter. Life is supposed to take place within the home or in the backyard. They are not places designed to encourage social interaction. Accordingly they discourage sense of trust and connection between people. Accordingly they lacks sense of familiarity and knowing strangers (Mark Granovetter 1983; Calthorbe ; Leyden 2003).

This study examines the relationship between neighborhood design and crime prevention. The main hypothesis is that pedestrian-oriented, mixed-use neighborhoods are more likely to encourage sense of safety and security than are car-dependent, single-use neighborhoods in Cairo - Egypt.

\section{Research problem and methodology}

Recently, a high crime rates and the reduced household's sense of security and safety become a fact. It raised an urgent need for studying the impacts of neighborhood urban 
form on increasing sense of security and safety on one hand and reducing crime rates in the other hand. In the past, traditional urban form had elements such as overhangs, small courtyards and decorative bollards around alleys to increase security. Contemporary neighborhoods used a fortification Elements and technological methods to cope with crime acts. Regardless of reinforcement methods (fortification, guards, and any other instruments), a passive crime prevention design without using guard tools need to be clarified. Neighborhood urban form can play a significant passive role in creating secure and low crime environments. It can also play an important passive role in shaping households perception of safety and security.

This study aims to test the correlation between the configuration of the street network patterns, land use patterns and housing patterns and crime opportunities. Regardless of the used traditional and technological barriers tools, this research concerns to study the impacts of urban form in itself. To define how it can affect sense of security. Based on a case study in four residential neighborhoods, adjacent to two criminal focal points in Cairo-Egypt, the research assesses the role of neighborhood urban form in reducing crime rates; Also it assess its impacts on residents' sense of safety and security.

This research assumes that the way we design our neighborhoods affects crime prevention and sense of security. And that contemporary neighborhoods rather than achieve low crime rates and high sense of security it could cause a security problem.

The method used is inductive which involves a comparative analysis of different case studies adjacent to crime points, with different spatial configuration. It aims to test and compare the relation between neighborhood urban form and residents' perception of safety in one hand and crime rates in the other hand.

The research depends on two interlocking stages: first, literature review to introduce the variables of the research, crime opportunities, crime prevention, and sense of security and safety in terms of concept, and measurable variables in addition to the introduction to neighborhood form in terms of concepts, patterns and measurable indices. Finally, the relationship between the two variables is tested in a case study in two neighborhoods adjacent to criminal points.

The field study goes through the following three steps: measuring the residents' perception of safety using questionnaire, measuring crime rates based on recorded municipal data, and measuring the spatial configuration using spatial measures in each case study and finally testing the validity of their relations.

\section{Crime rates and Neighborhood design}

The existence of criminal points inside urban fabric presents a risk to adjacent residential areas by increasing crime rates and crime opportunities. Adjacent residential areas are faced with a risk of crime against properties in term of house break-ins, vehicle theft and criminal acts against residents them self's in neighborhood streets. The criminal acts of offenders against residential neighborhood, present a risk to its residents. The impacts of such criminal points to adjacent areas impact the level of resident's sense of safety and security in their residential areas. 
A reduction of resident's sense safety in their community can reduce their sense of belonging, participation and engagement with others in their community. Low sense of security can reduces social capital and cohesion of the community.

Different approaches are used to reduce crime opportunities, reinforcement methods using physical instruments like gates and fences, monitoring and electronic gates, and alarm systems, and security members. The other approach is the environmental approach that supposes that urban form can be designed in a manner that self-reduces crime opportunities. A certain design of physical layout, land use pattern, street network pattern, and housing pattern could reduce crime opportunities and increase resident's sense of safety and security. A branch of research called crime prevention through environmental design (CPTED) is developed to enhance the efficiency of urban form to defend its residents against crime opportunities that might impact due to the adjacency to criminal focal points.

This field depends on sociological issues regarding the offenders who fair to be seen and look for concealment opportunities to assist them commit their crimes without been caught. Increasing offender's chances of being seen and caught reduces crime opportunities. The bulk of research on this rests on four easy to investigate factors: surveillance, control of access, territoriality, and social interaction between community residents.

Natural Surveillance means a continuous observation for residents and their properties in streets, urban spaces and buildings. It makes offenders feel that they are observed, accordingly reduces crime opportunities. The purpose is not to keep them out but to make them be under complete observation and feel that they are observed. The natural observation as by product of daily activities can reduce crime opportunities, (Crowe, 2000; Newman's, 1973; Desyllas et al., 2003).

Control of access points, and functional hierarchy, it starts from the public to semipublic and to the private. It restricts the existing of who are allowed to be here, and keep out who do not have reason to be in place. Offenders fair to be asked for the reason they are in this place. Barrier makes it unattractive to potential criminals (NCPC, 2003).

Define of territoriality, natural boundaries between public and private define private territoriality and make residents naturally protect their territoriality they feel as their own. It increases user's familiarities with each other and accordingly discourages offenders (Geason S. 1946).

Social interaction, it depends on how to increase resident's interaction to make them know each other and accordingly distinguishes who are strangers in the community. It enables collective involvement efficiency to define strangers and especially offenders and to face their criminal acts. This criterion rests on some questions: to what degree it allows clear sight line?' minimize isolation? And to what degree it increase residents ability to know and define neighbors, strangers, and criminals. These criteria can be measured using observation and questionnaire. 


\section{Urban Pattern Characteristics and crime prevention}

The Correlation between crime opportunities and urban form has been frequently found in numerous studies. A current debate exists between scholars for the role of modern versus traditional patterns in their impacts on crime prevention.

Regarding land use pattern some scholars found mixed land use residential areas is a key for achieving safety in urban spaces. They consider that high mixed land use with variation of activities attracts people continuous movement during day and night, and accordingly assures the continuous natural surveillance and accordingly it provides residents with sense of safety and security (Bahamam 2001; Camona 1997). They found that complete remove of nonresidential uses from residential area could create negative spaces (negative space theory), a space that do not have any subsidiary functions or activities that rather than become a positive space that attracts residents into a negative space that reject and discourage residents to be socially engaged. Despite, these types of spaces remove the natural surveillance and accordingly make spaces a place of attraction for criminological behavior. They found that urban spaces must serve more than primary function, preferably more than two. (Al Hamad, 1995; Kamona, 1997).

On the contrary other scholars found that minimizing variation, diversity and mix of land uses could reduce users and accordingly they can be defined and accordingly strangers can be defined and criminals also. They found that increase nonresidential uses to residential areas could reduce resident's appetites to define strangers and accordingly increase crime rates (Angle 1995; NCPC 2003).

Regarding housing income mix, some scholars found that mixed housing income is expected to reduce crime rates and increase sense of security; it enables residents to interact with different social groups and encourage sense of trust and sense of connection between residents. This could increase sense of familiarity of other housing income groups and create social web of public respect and trust (Jacobs 1961; Leyden 2003). According to the 'intergroup theory', more diversity implies more inter-ethnic tolerance and social solidarity. The more contact with people unlike, make residents can overcome initial barriers of ignorance and start to trust them (Hooghe, M., 2007, Putnam 2000). For them ethnic diversity may reduce criminality and increase sense of safety and security.

On the contrary, other scholars found that separate income could achieve homogeneity between residents, accordingly shared values and interests. No social tension exists between community residents. According to the 'constrict theory', suggest that ethnic diversity might reduce both in-group and out-group trust, in neighborhoods where ethnic diversity is higher trust become lower. The reason is that ' when the social context is more diverse in terms of ethnic groups, there are more people 'unlike you'. As a result, there are less people each resident can identify, resulting in fewer social connections and lower levels of trust (Hooghe, M., 2007). For them ethnic diversity may encourage criminality and reduce sense of safety and security. 
Regarding Housing income difference between neighborhood and adjacent community, some scholars found that locating similar low income neighborhood near to poor criminal community reduces social tension between residents and accordingly reduce crime rates. On the contrary, other scholars found that locating high income neighborhood adjacent to poor community could increases social benefits through creating a relation between different social groups; it creates much more social capital. It reduces social tension and accordingly reduces crime rates (Butman, 2000; Hillier 1984).

Regarding street network pattern, some scholars found that modern hierarchical street network pattern could define territoriality, achieve natural surveillance, and create security parries, they recommends that moving from public grid pattern to private culde-sac pattern could increase factors of safety and reduce crime rates. Cul-de-sac patterns are pattern that Newman stresses in his theory of defensible space to exclude the intrusion of strangers in the space (Neuman, 1972).

On the contrary, other scholars found that moving to public grid give streets the byproduct of movement, through movment that make it become more save. It increases streets critical role of urbanity and natural survilliance and accordingly it is not a place for enhancing crime. (Carmona, 2003; Worth, 2005, Calthorbe, 2001; Hiller, 1989).

Regarding building height, some scholars found that taller buildings height increase building density and community size, accordingly it increase probability of strangers in urban spaces accordingly reduce sense of safety and security (Bahamam, 2001; Newman, 1996).

Regarding to density and community size, some scholars found that increasing density provide community with sufficient dense concentration of people that avoid empty spaces and make spaces full of people and assure surveillance. On the contrary, other scholars found that increasing community size makes it difficult to define users, strangers and accordingly to define criminals.

Regarding urban hierarchy, some scholars consider urban form hierarchy is a good tool to define territorialities, responsibility and control to urban spaces. It isolates private spaces from public spaces to assure privacy that enhance natural surveillance, and definition of strangers and accordingly enhance safety and security. (Bahamam, 2001). They found that the cluster closed pattern surrounding public spaces, give the space some degree of privacy and territoriality that make residents easily can define strangers. It provides a sense of safety against intrusion, and accordingly increase sense of safety and reduces crime opportunities (Bahamam, 2001; Newman, 1972; NCPC, 2003). On the Contrary, other scholars found that the traditional grid pattern.

Accordingly a current debate exist between scholars to define the role of modern versus traditional neighborhood characteristics in reducing crime rates and increasing residents sense of safety and security. The following part of the research is developed to test the validity of such assumptions in the case of Cairo Egypt. 


\section{THE Case Study of Four Categories of Neighborhoods Adjacent To Two Criminal Focal Points in Cairo}

The objective of this research is to trace any statistical significant differences in responses to crime rates and resident's sense of security and safety across different categories of neighborhoods adjacent to criminal focal points. The case study based on four categories of neighborhoods adjacent to two criminal focal points in Cairo. The relationship between neighborhood design and crime prevention will be examined. El Mothalth-Helwan, and El Hagana-Nasr City are two chosen locations, they have recorded highest crime rates in Cairo, according to National Center for Social and Criminological Research. These two focal points were surrounded by a variation of neighborhood types ranging from traditional mixed-use, pedestrian-oriented neighborhood to the contemporary separate use-car oriented neighborhood.

\subsection{Selection of case study areas:}

Four neighborhoods were selected to present different categories of physical and social attributes, as shown in Figure 2. They should satisfy variables incorporated within the proposed model. Based on the following criteria:

- Locations to be adjacent to areas of criminal focal points, two locations are selected Al mothalth - Helwan and El Hagana - Nasr City, as they are recorded to have higher values of criminals as recorded by National Center for social and criminological research (NCSCR).

- In each location, two neighborhoods ranging between traditional and contemporary are selected to meet the variables involved in the study regarding configuration difference in urban form and social attributes including the historical development, street network patterns, land-use pattern, housing patterns, population demographics and household characteristics.

Figure (1) Case Study Selection (Two locations in Greater Cairo Region)

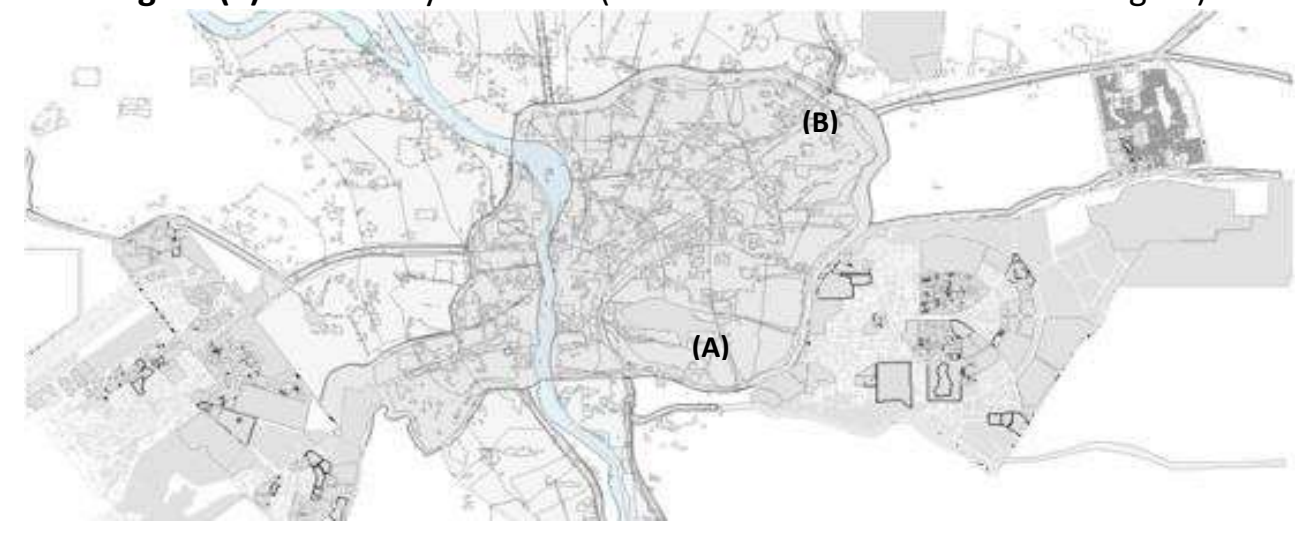


Figure (2) Case Study Selection (Greater Cairo Region)

A) El Mothalth (Helwan)

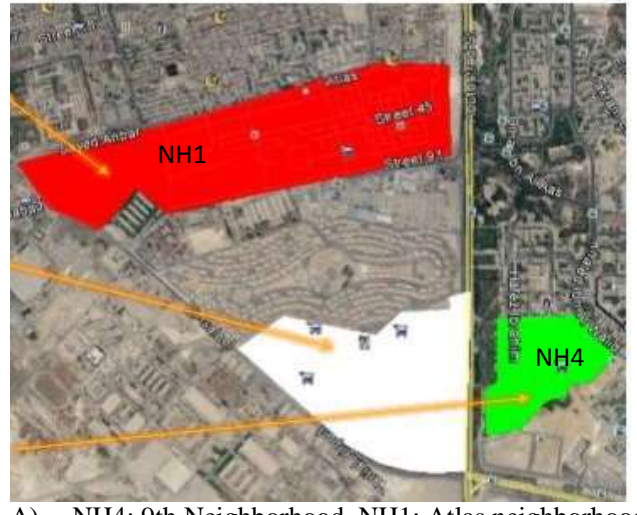

A) NH4: 9th Neighborhood, NH1: Atlas neighborhood.
B) El Hagana (First District Nasr City)

B) NH3: $9^{\text {th }}$ neighborhood, NH2: Officers neighborhood.

\subsection{Data collection and classification:}

The purpose is to measure the impact of criminal focal points on adjacent neighborhoods, and to define the role of adjacent neighborhood urban form to defend and face the crime opportunities and provide residents with sense of safety. Two forms of data collection were used - the first to measure urban form patterns, and the other to measure social data represented in the crime rates and opportunities and residents satisfaction to safety and security in their neighborhood. Finally, the correlation between both is measured.

\subsubsection{Measurements of Neighborhood urban configuration patterns:}

Urban form data were collected using surveying maps, observation, satalite maps, photographic images to document and explore neighbourhoods urban configuration patterns including land-use pattern, housing income pattern, street network pattern, and other urban spaces charachterstics including density, urban form, building heights, urban herarcheiy, and walkway forms, and finally landscape elements including lighting, greening. The data gathered for each case study related to urban configuration for each neighbourhood are gathered, measured and scored in Table 2. Recorded urban form data is categorized starting from the traditional type ending with the modern type and the scored result is converted into percentage, with keeping traditional pattern as higher percentage value than modern patterns.

1- Land use pattern can be classified under heading of landuse type, variation and density. The (dividing vs. connecting) line between different land-use represents the degree of mixed vs. separation of landuse (Ghonimi et.al, 2011).

2- Housing pattern can be classified under heading of housing type, variation and density; they can be measured using the (dividing vs. connecting) line between housing types. It represents the exclusion vs. segregation of housing types as a manifestation of political regime (Ghonimi et.al, 2010).

3- Street network pattern can be classified under three categorize grid, loop, and tree patterns. Their spatial structure can be classified under heading of type of 
street, Linear feet of streets, No. of blocks, No. of intersections, No. of access point, No. of cul-de-sacs, Percentage of streets area.

4- Building Height ranges between low height 1 to 3 floors, mid height 4 to 5 floors, and tall height 6 to 8 floors.

5- Community Density range between low density (60Person/Fedan), Middle density (120 Person/Fedan) and High Density (200 Person/Fedan) Also community size is measured and ranged between small, medium and large community size.

6- Urban form hierarchy is ranged in one hand between public, semipublic, and private in the other hand between grids versus cluster.

Selected neighborhoods were subjectively categorized into four ideal types, that range between modern cars oriented, separate use, single housing income, low density and treed oriented street network. And traditional pedestrian oriented, mixed-use, mixedhousing income, high density, and grid oriented street network. In most of the following analysis, the neighborhood arranged according to such categorization to present the social impacts of crime rates, and sense of safety and security moving between these categorize.

Table (1) Main spatial characteristics of Case Study Area.

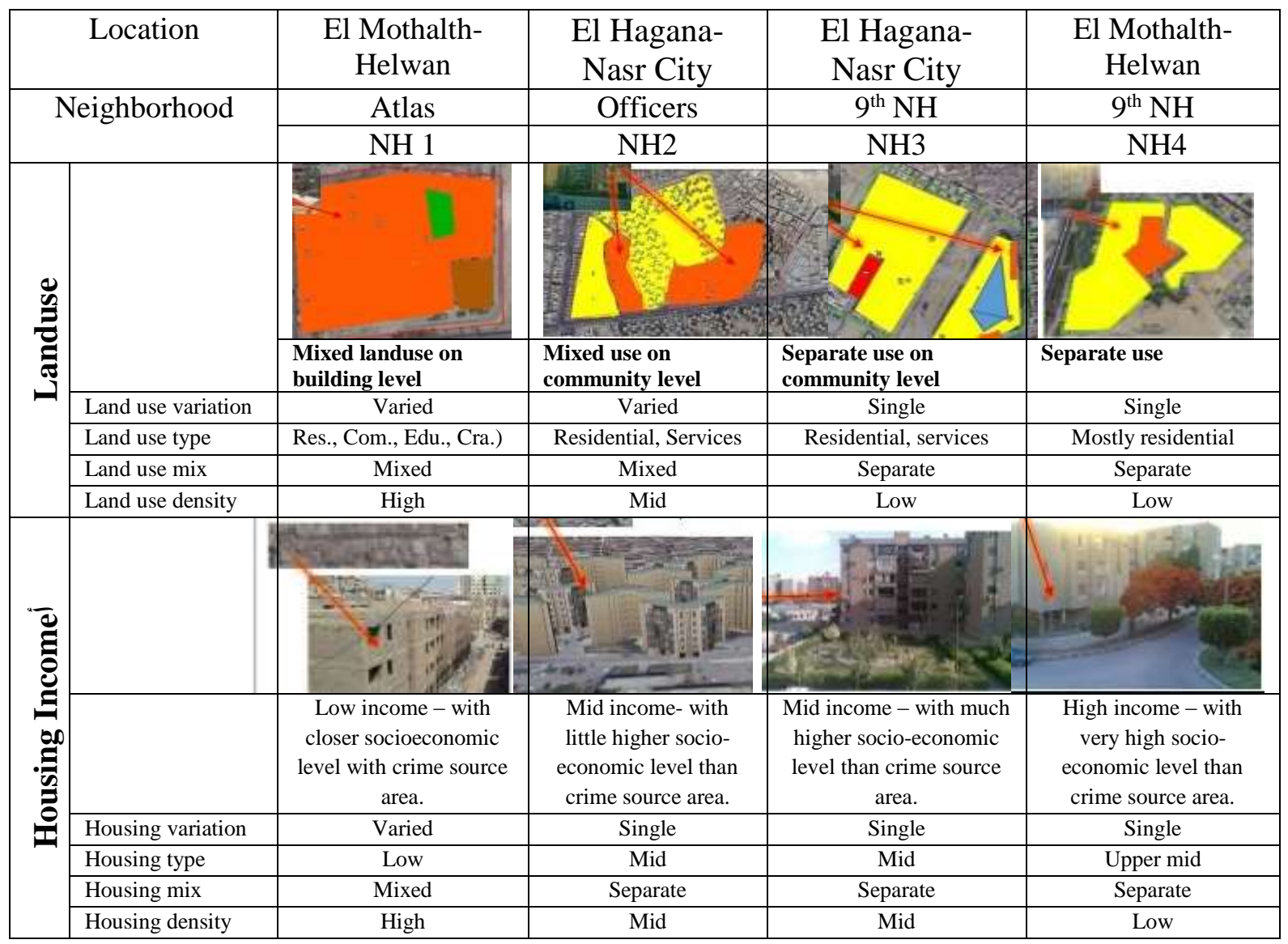




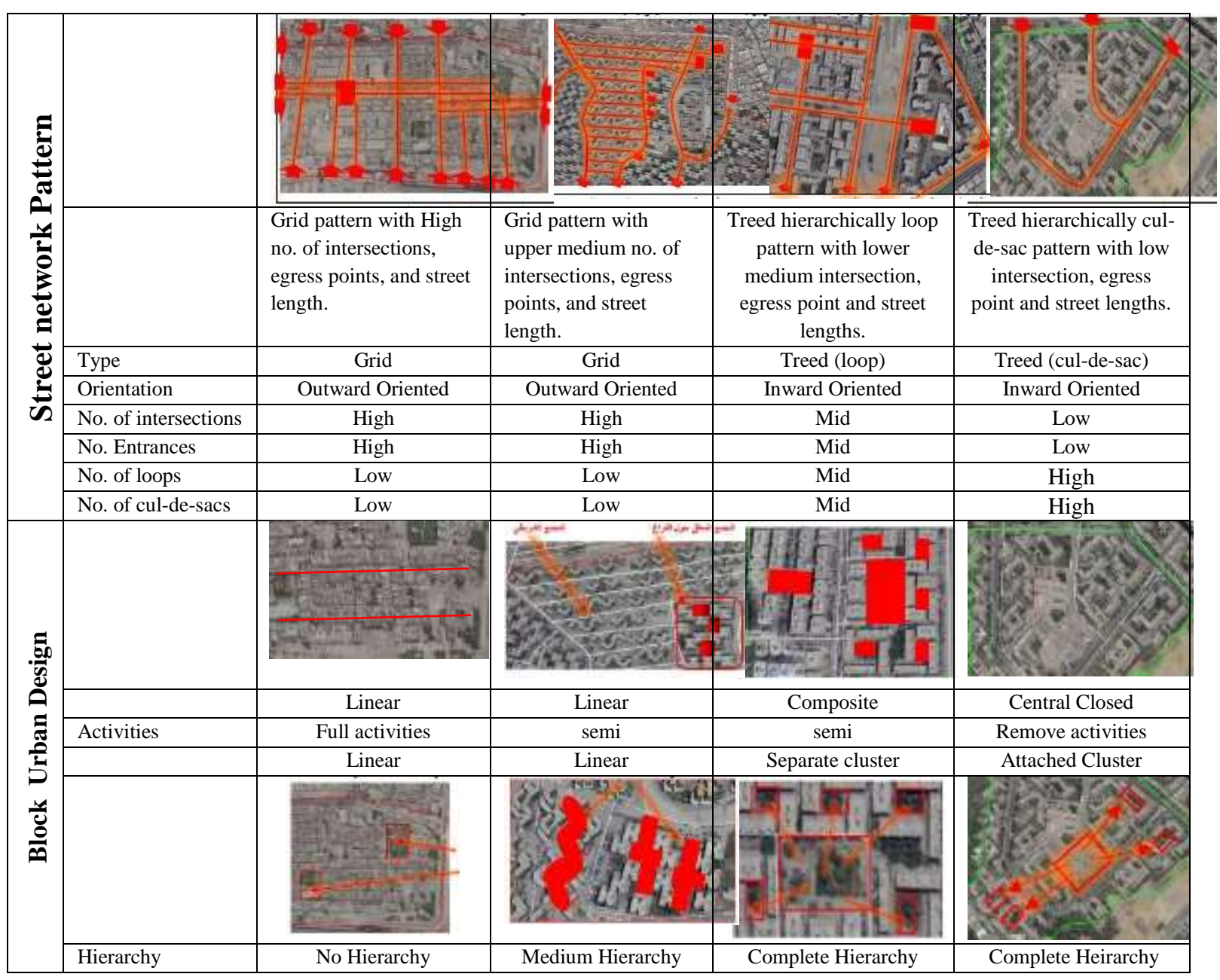

\subsubsection{Measurements of Crime rates and sense of safety and security:}

Two ways are used to measure crime prevention based on crime rates, and sense of safety and security. The first depends on the actual reported crime rates and the other depends on resident's satisfaction to sense of safety and security.

\subsubsection{Crime Rate Measure:}

The first measure is crime rates; it is based on data that have been reported by the police station responsible for each location. The reported crime rates are converted into percentage to enable the comparison between the four neighborhoods. The neighborhood with heights crime value has taken $100 \%$, and the percentage of total crime reported for the four neighborhoods as listed in Table (2).

Table (2) represent recorded crime rates in no. and percentage (Reference: NCSCR).

\begin{tabular}{|r|c|c|c|c|}
\hline & NH 1 & NH2 & NH3 & NH4 \\
\hline Crime Rates & 214 & 153 & 91 & 7 \\
\hline Percentage & $100 \%$ & $71.5 \%$ & $42.5 \%$ & $3.2 \%$ \\
\hline
\end{tabular}




\subsubsection{SENSE OF SAFETY AND SECURITY MEASURE:}

It is based on a questionnaire administered to district residents. The questionnaire was designed to explore the influence of urban form of affected districts, adjacent to criminal focal points, to their residents' perception of safety and security. Sample selection: 40 residents are randomly selected in each case study area. The questionnaire measured the key factors of crime prevention. A five points Likert scale ( 1 to 5 ) were used and have been converted into percentage scale.

Questions first explore resident's socio-economic characteristics then it investigates their satisfaction to sense of security and safety as well as to reciprocity, familiarity and trust in neighbors, i.e. how they well feel safe and secure for their families, children and wifes to move freely in the community, and for their properties. How well they knew their neighbors, how well they trust or faith in other people, and their social engagement. These dependent variables were measured as described in the following paragraphs:

The variable "know strangers measure" was measured whether and to what degree residents be able to recognize strangers that pass by in front of their houses and passing in the recreational area.

The variable "feel of safety and security measure" was measured whether and to what degree residents feel safe for movement in streets, in parks and facilities, safe in homes, safe for properties, safe for wife and kids and all age group people. For what degree he feels safe during day hours, during night hours, till late night. These questions probe the degree to which resident's perception and sense of safety and security.

The variable "social engagement with neighbors' measure" includes whether and how well they know their neighbors inside the community, and the adjacent community (source of crime). How many times they share them in vacations, invited them to their homes, and is invited to their neighbor's homes; these questions probe the degree to which resident engage with their neighbors.

The variable "feel of trust measures" measures whether residents felt that their neighbors could be trusted, whether they thought people were fair, and whether they thought most people try to be helpful.

The variable "surveillance measures" measures whether residents inspect the external surroundings when they are inside their house.

The variable "target hardening measures" measures whether residents need to install alarms and technical instruments in their houses and properties to achieve security purposes.

All previous measures are used to create a variable called "neighborhood crime prevention measure" which is an additive index of the all variables. It have been gathered, measured and scored in percentage in Table 3. 
Table (3) Measured Neighborhood resident's satisfaction in percentage.

\begin{tabular}{c|c|c|c|c}
\multirow{2}{*}{ Assesment factors } & & & & \\
\cline { 2 - 5 } & NH1 & NH2 & NH3 & NH4 \\
\hline Know strangers & $30 \%$ & $75 \%$ & $70 \%$ & $45 \%$ \\
\hline Sense of Safety & $40 \%$ & $85 \%$ & $72 \%$ & $50 \%$ \\
\hline Feel of trust & $40 \%$ & $85 \%$ & $75 \%$ & $55 \%$ \\
\hline Survillience & $30 \%$ & $75 \%$ & $70 \%$ & $55 \%$ \\
\hline Target hardening & $40 \%$ & $70 \%$ & $80 \%$ & $50 \%$ \\
\hline Fear of crime & $50 \%$ & $75 \%$ & $60 \%$ & $55 \%$ \\
\hline Sum Percentage & $38 \%$ & $78 \%$ & $71 \%$ & $55 \%$
\end{tabular}

\subsection{Results and discussion:}

Neighborhoods are arranged starting from the traditional mixed use, high rise, and high density, grid street pattern to the contemporary sprawl separate use, low rise, low density, and tree street network pattern. Both crime rates measures and crime prevention measure were transformed into percentage in the four neighborhoods. Their values are compared with neighborhood socio-spatial factors. The correlation between them as dependent and independent variables respectively, for the four neighborhoods are measured as follow:

Traditional neighborhoods ( $\mathrm{NH} 1, \mathrm{NH} 2)$ recorded lower crime rates which tend to remain vibrant and active during day and night hours. On contradict with resident's sense of safety and security, who found their community unsafe from inclusion of services inside the residential area, they fear the close proximity of services to their homes, as well as unwanted, and unfamiliar intrusions and congested streets. They think that this causes a lack of safety and increases crime opportunities. They keep their children away from streets to avoid accidents and intrusions.

Contemporary neighborhoods (NH3, NH4) recorded higher crime rates which tend to remain vacant during night hours. On contradict with resident's sense of safety and security, who found their community provides higher sense of security and safety, quieter and safer streets and urban spaces, where children can play with minimal fear of fast moving traffic. It provides a sense of safety against intrusion and unfamiliar persons, and reduces the crime opportunities; they found safety through excluding the others.

A comparison between resident's satisfaction and crime rates reveals that, resident's satisfaction to sense of safety doesn't align with recorded crime rates. Moving from traditional neighborhood to contemporary neighborhood increases crime rates, and reduces resident's sense of security and safety. In Figure (3), both residents of traditional and modern neighborhood were slightly less likely to have a greater feeling of security than in moderate neighborhoods. In the other hand traditional neighborhood is marked by a lower crime rates than in modern neighborhoods. 
Figure (3) Relation between recorded crime rates and residents satisfaction to safety.

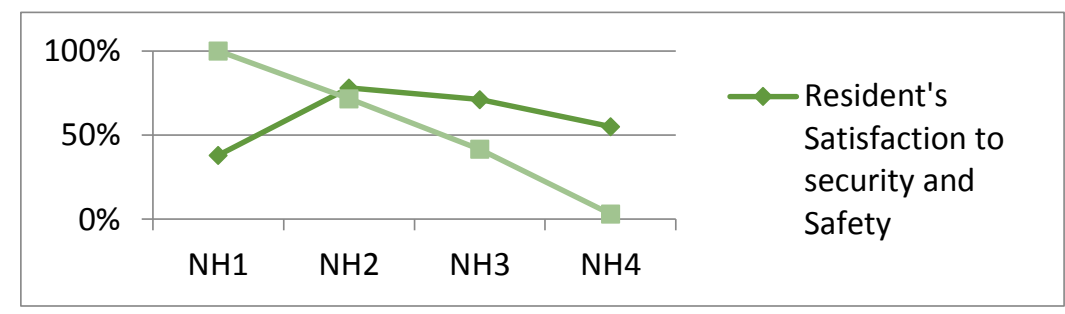

\subsubsection{The relation between Crime Prevention measure and land use pattern:}

Figure (4), reveals that crime rates increase with moving from mixed to separate use neighborhoods. This is because separate communities promotes interaction through neighboring familiarity; there are no intrusions or passers-by, only neighbors who exist in urban spaces; residents mostly know each other to provide high crime prevention ratio.

On the other hand resident's satisfaction to security and safety issues is reduced in both high mixed and high separated land use pattern. In high mixed community's residents found that streets are full of unknown intrusions that reduce trust of others, accordingly they fear to meet others resulting in reduced interaction, and they want to take their children away from the streets. Also in separate use communities, residents found streets as empty, it lakes surveillance and complete supervision. An optimum mix could cause acceptable values of sense of security and safety.

Figure (4) Relation between land use and crime prevention (crime rates-satisfaction to safety).

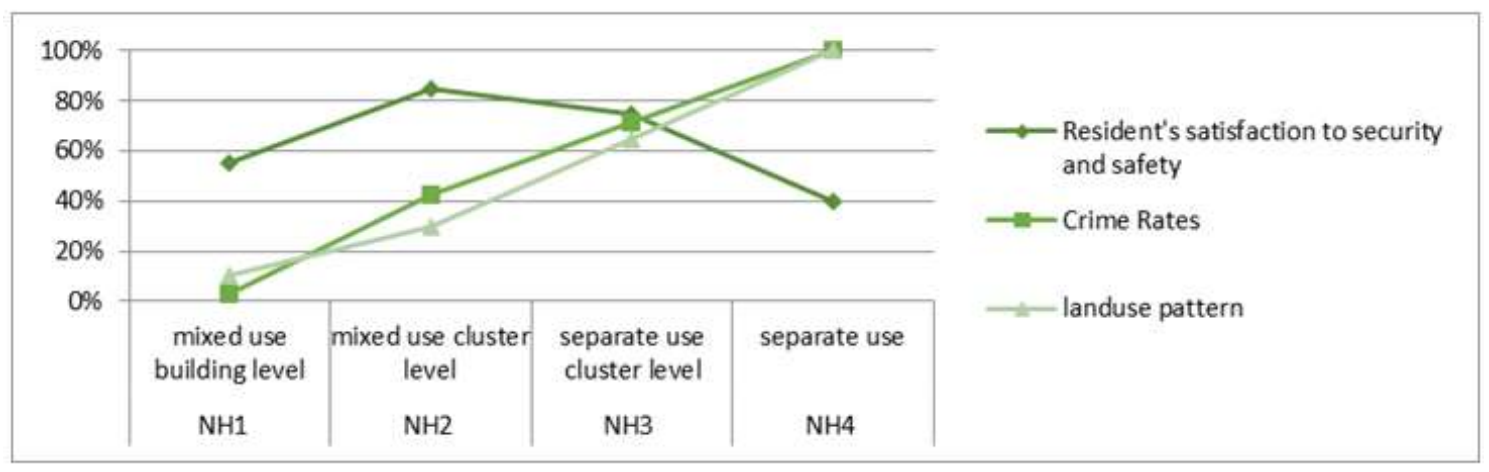

\subsubsection{The relation between crime prevention measure and housing income pattern:} Fig (5) indicates that crime rates are increased with moving from low income to high income community, this is due to the high social gap between the community and the adjacent low income crime focal point community. It causes social exclusion with adjacent low social classes, so it creates poles of social tension between the poor and the rich hence enlarge the sense of criminality and vandalism. 
On the contrary resident's satisfaction is reduced in high income community, where a type social tension is measured, high income residents fair the intrusion of low income offenders, they use different reinforcement methods using physical instruments like gates and fences, monitoring and electronic gates, and alarm systems, and security members. Also low income residents feel unsafe they. On the other hand mid income and upper mid income residents feel safer in their communities.

Figure (5) Relation between housing income pattern and crime prevention (crime ratessatisfaction to safety).

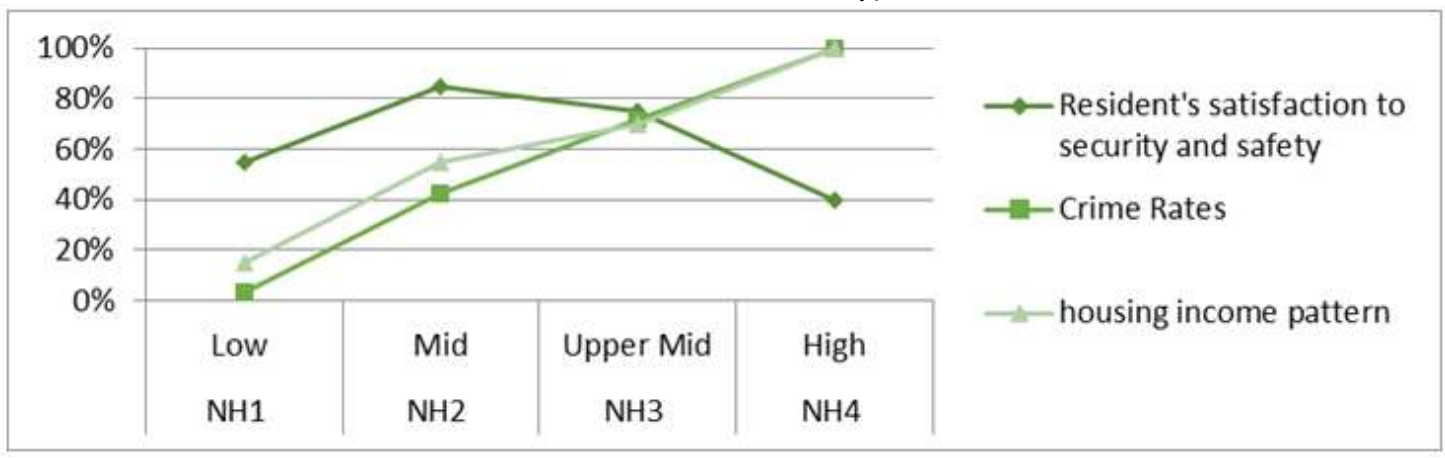

\subsubsection{The relation between crime prevention measure and street network pattern:}

Figure (6) indicates that crime rates is reduced with moving from grid to treed street network pattern (loops and cul-de-sac) and specially with defining entrances this due to high surveillance value, high territorialities and relationship between residents that make them know each other and define strangers.

On the other hand resident's satisfaction to security and safety issues is reduced in both cases of very grid pattern and very tree cul-de-sac pattern. The first reduces territorialities and increase the through pass that makes offenders are not recognized within strangers and passengers. The second reduces through movement of people which reduce their eyes continuous vision on the streets. An optimum value is highly accepted.

Figure (6) Relation between street network pattern and crime prevention (crime ratessatisfaction to safety).

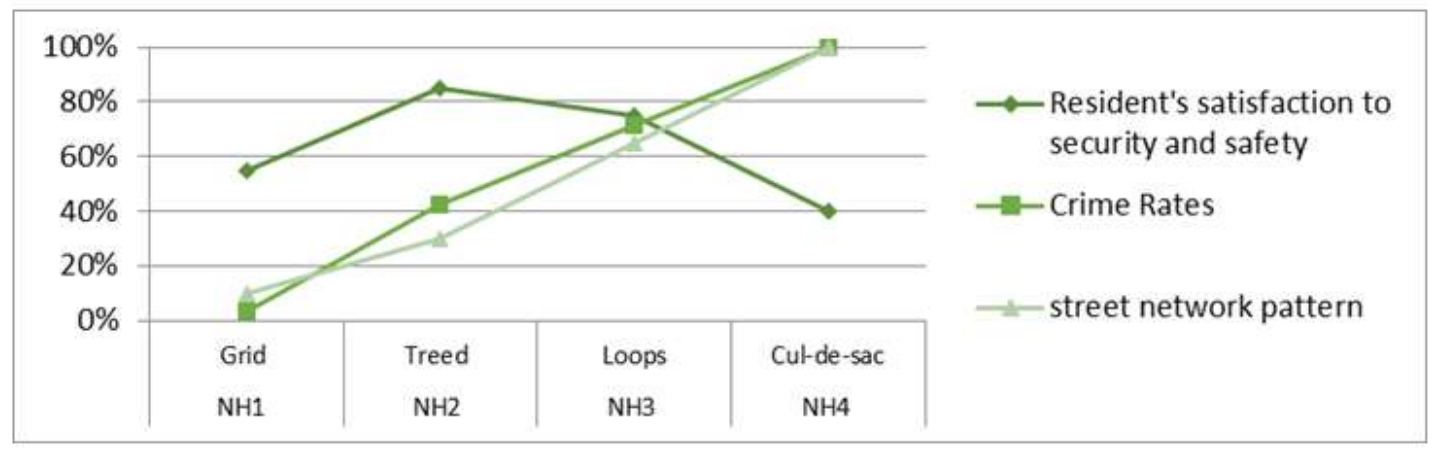




\subsubsection{The relation between Crime Prevention measure and Density pattern:}

Figure (7) reveals that crime rates increases with moving from low density to high density community. This can be explored because increasing density causes a relevant increase in community size that makes Residents hardly know each other and hardly acknowledge strangers. The reduced interaction, mutual relationship, and reciprocity between residents cause unsafe streets.

On the other hand resident's satisfaction to security and safety issues is reduced in both cases of very low and very high density. The first reduces community size and reduce resident's surveillance to the community. The second is increases community size and accordingly reduces residents familiarity of neighborhoods, and increase the chance of entering offenders between community residents without been known. An optimum value is highly accepted.

Figure (7) Relation between housing density pattern and crime prevention (crime ratessatisfaction to safety).

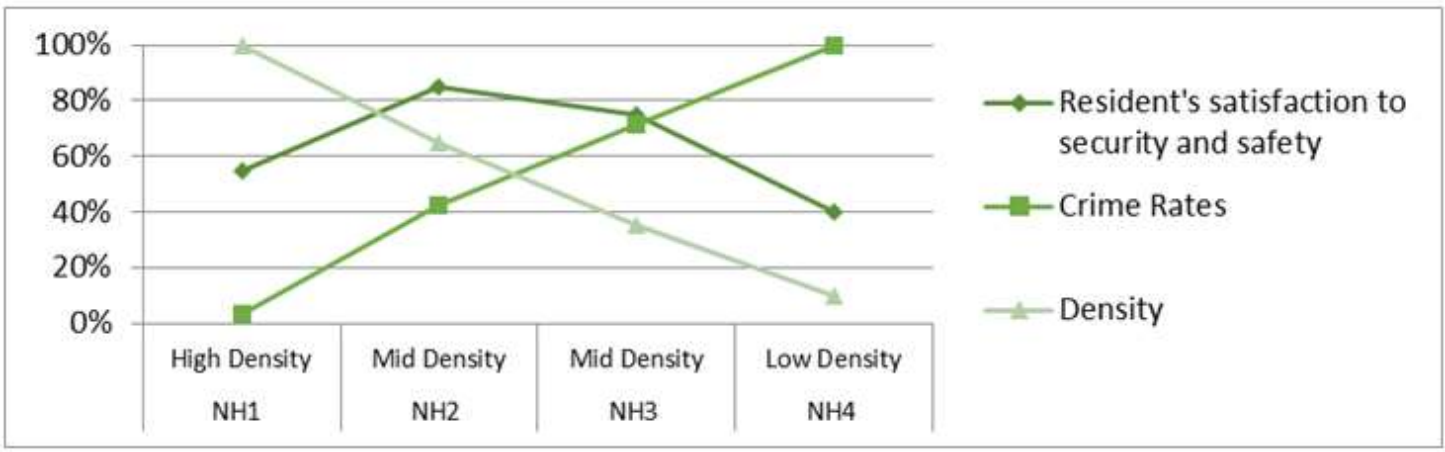

\subsubsection{The relation between crime prevention measure and urban form pattern:}

Fig (8) indicates that crime rates are reduced with moving from grid arrangement to cluster arrangement; this is due to the strong relationship exist between neighbors that makes them easily define strangers. On the contrary resident's satisfaction is reduced, they.

Figure (8) Relation between urban form pattern and crime prevention (crime rates-satisfaction to safety).

\begin{tabular}{|r|c|c|c|}
\hline $100 \%$ & & \\
\hline
\end{tabular}




\subsubsection{The relation between crime prevention measure and activities pattern:}

Fig(9) indicates that crime rates are reduced with moving from urban spaces with no activities to spaces crowded with activities, since a continuous supervision and surveillance are exist. On the other hand resident's satisfaction to safety factors is reduced in both spaces with no activities and spaces crowded with activities; in the first case they lost the surveillance to urban spaces, on the second case they cannot define strangers and criminals.

Figure (9) Relation between spaces activities pattern and crime prevention (crime ratessatisfaction to safety).

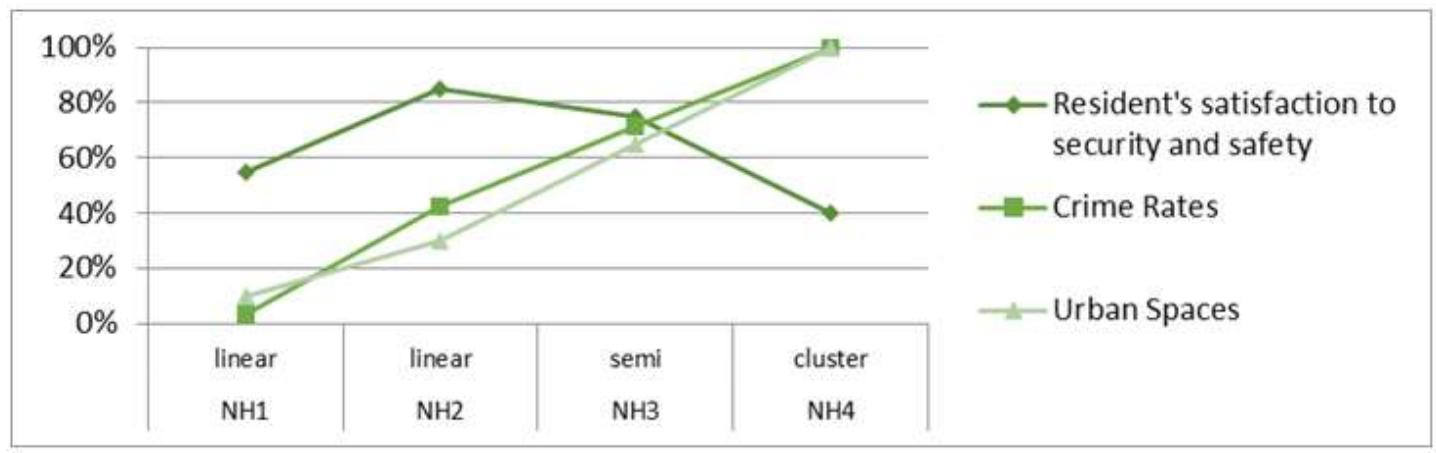

\subsubsection{The relation between crime prevention measure and building height pattern:} Figure (10) indicates that crime rates are reduced with increasing buildings height, as it cause higher density and community size, it enhance the continuous supervision and surveillance to urban spaces. On the other hand resident's satisfaction to security and safety factors is reduced in both neighborhoods with lower and higher buildings height; in the first case they lost the surveillance to urban spaces, on the second case they cannot define strangers and criminals.

Figure (10) Relation between buildings height pattern and crime prevention (crime ratessatisfaction to safety).

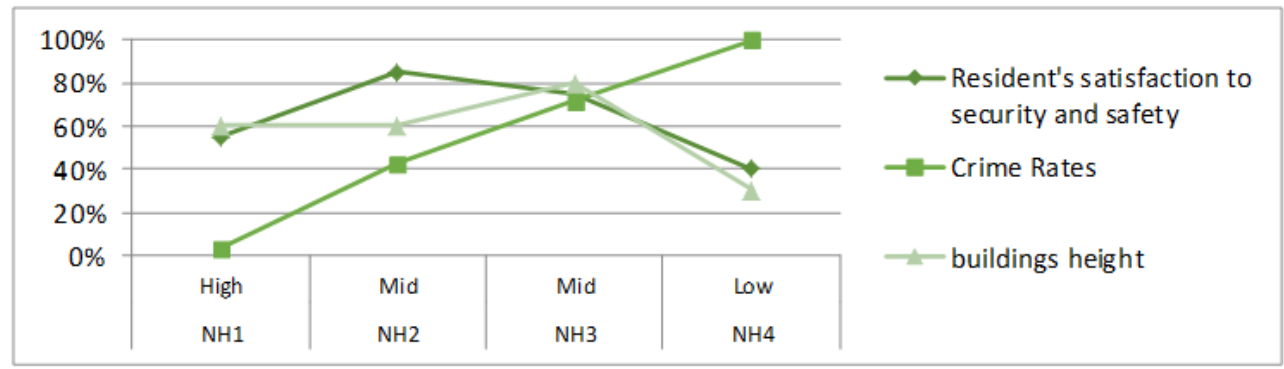

\subsubsection{The relation between crime prevention measure and hierarchy urban spaces:}

Fig(11) indicates that crime rates are reduced with increasing urban hierarchy of urban spaces, it increases sense of territoriality and makes it become a destination place that lake through pass and by pass product. That makes them easily define strangers. 
On the other hand resident's satisfaction to security and safety issues is reduced in both cases of grid and treed pattern. The first increase the through pass and increases the unwelcomed persons of the outer community. The second reduces moving persons in streets beside it makes residents completely depend on car movement to cover the large moving distances, the matter that reduces moving pedestrian. An optimum value is highly accepted.

Figure (11) Relation between urban spaces hierarchy pattern and crime prevention (crime ratessatisfaction to safety).

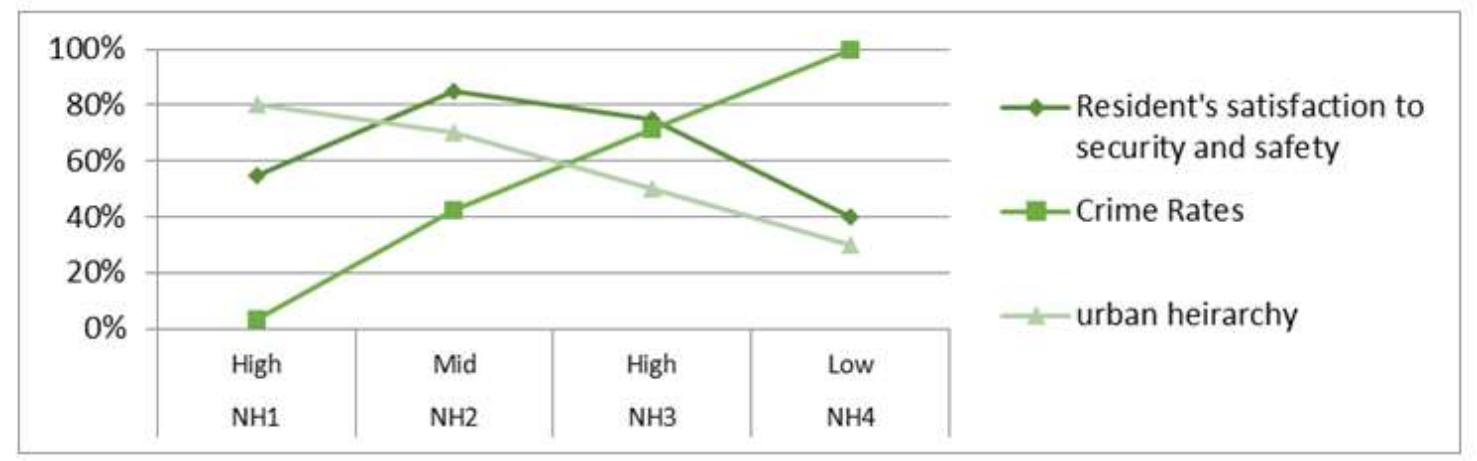

This result suggests that traditional neighborhoods that are mixed use, higher in height with higher density, and grid street network oriented, will be higher in their level of crime prevention than modern car suburbs that are separate use, lower height with lower density, and treed oriented street network.

On the other hand residents satisfaction to safety and security issues are reduced in both cases of traditional, mixed use, high density, and grid street network, and modern, separated use, low density, tree oriented network and car oriented. The first increase density, community size, and existence of strangers and accordingly reduce chance that residents can define and recognize offenders. The second reduce density and remove nonresidential uses that make street are free of passengers that make it become a place that lake surveillance and enhance criminal acts.

A moderate values provide more safe community, mid density, mid mixed use, midlevel, and loop street network are mostly viable to be traced and placed adjacent to criminal low income neighborhoods. It proved its efficiency in facing criminal acts of offenders than the extreme traditional neighborhood with high density, low income, grid street network, and mixed use neighborhood and efficient than the other extreme of contemporary neighborhood with low density, high income, separate use, and treed street network pattern. 


\section{CONCLUSION AND RECOMMENDATIONS}

This research suggest that the way we design our neighborhoods affects crime prevention and crime rates and thus affects resident's sense of security and safety. The results indicates three conclusions, the first indicate that fear of perception does not coincide with crime rates accordingly they should be studied separately.

The second regarding residents sense of safety, it indicates that neither residents living in traditional, with extremely densification, mixed use on building level, and grid with high intersection points, nor residents living in modern neighborhood with extremely low density, separate use, and tree street network pattern, are more likely to feel unsafe, during day and night, at homes and in streets, and to feel unsafe for their family and properties. On the other hand, a residents living in moderate neighborhood model are more likely to feel safe, during day and night, at homes and in streets.

The third regarding crime rates, it is recorded that traditional districts compared to modern neighborhoods are more willing to reduce crime rates. It can mitigate the potential risk of criminal focal point to their residents.

Accordingly planners and urban designers are recommends to take in their consideration the impacts of physical characteristics on crime rates and residents satisfaction:

1- Good design should force a continuous activity in urban spaces, a spaces that assure not having negative spaces that increase surveillance

2- Good design that gives resident's participation a great role in urban design, to found what is suitable for their socio-economic conditions.

3- Both high mixed and high separate use community could encourage criminality. The first increase the existence of

4- Both high income and low income residents could encourage criminality. The first increase social tension with low income neighbors, and accordingly increase their offender's acts. The second enables residents to interact with different social groups and encourage sense of trust and sense of connection between them. This could increase sense of familiarity of other housing income groups. This could create social web of public respect and trust (Jacobs 1961; Leyden 2003).

5- Both grid and treed street network could encourage criminality. The first reduces territorialities and increase the through pass that makes offenders are not recognized within strangers and passengers. The second reduces through movement of people which reduce their eyes continuous vision on the streets. An optimum value is highly accepted.

6- Good design should provide hierarchy in urban spaces, from the public to the private, to improve resident's definition of territoriality, control of access and surveillance; accordingly it could increase sense of safety and security in urban 
spaces and at the same time increase social relation between residents and enhance social cohesion.

7- Both high and low buildings height and both high and low density could encourage criminality. The first increase community size to an extent that makes residents cannot define strangers and accordingly cannot define offenders. And the second reduce community size to an extent that makes residents cannot have a complete surveillance to their neighborhood. A moderate building height, community density, and community size values proved to be efficient in crime prevention near criminal points.

A further research with more case studies needs to be carried out to obtain clear conclusions of the relationship between crime and neighborhood patterns.

\section{References}

Alhamad, A.(1995) " Urbanization and Criminology), Arabic Centre for Safety studies, Riyadh.

Atkins, S., Husain, S. and Storey, A. (1991). The influence of street lighting on crime and fear of crime. Crime Prevention Unit Paper Number 28. Crown Copyright, London.

B. Hillier and J. Hanson, The Social Logic of Space, Cambridge University Press, 1984.

Bahamam, Ali Ben Salem (2001), "Hiring Urban design to achieve crime prevention in residential areas" journal of since, medicine and engineering Om El Kora University.

Berube, A. (2005) "Mixed communities in England: A US perspective on evidence and policy prospects" Joseph Rowntree Foundation.

Calthorpe, P. (2003), "The Regional City", time saver - standards - for urban design, p. 1.5-1

Cozens, P. M. (2002). Sustainable urban development and crime prevention through environmental design for British city, Towards an effective urban environmentalism for the 21st century. Cities, 19(2), 129-137.

Crowe, T. (2000). Crime prevention through environmental design: Applications of architectural design and space management concepts (2nd Edition). Oxford: Butterworth-Heinemann.

Gardner, Robert A.., CPP CSP; 1981 and 1995; Crime Prevention through Environmental Design; Security Management Magazine.

Gnanasambandam Subbaiyana* and Srinivas Tadepalli (2012), " Natural Surveillance for Perceived Personal Security: The Role of Physical Environment", Journal of American Transactions on Engineering \& Applied Sciences.

Howe, Dorinda R., FCPP, CPTED Specialist; 1998; Crime Prevention through Environmental Design; National Crime Prevention Institute; written for the City of Orlando.

Hillier, B. et. al. (1989). The Spatial Pattern of Crime on the Studley Estate. London: Unit for Architectural Studies, Bartlett School of Architecture and Planning, University College London.

Jacobs, J. (1961), The Death and Life of Great American Cities, New York: Vintage Books, 1961. 
Kamon, Heidar, (1997) " The relationship between urbanization and criminology), El Maousoa Journal (405).

Leyden K. (2003) " Social capital and the built environment: The importance of walkable neighborhoods" American Journal of Public Health, vol 93, No9.

Lofland, Lyn. 1973. A World of Strangers: Order and Action in Urban Public Space. New York: Basic Books.

Macarena Rau, (2004) " Civic Safety and Residential Urban Space Natural surveillance in community appropriation limits" 9th Annual International CPTED Conference.

McKay, Tom; July, 1997; Empty Spaces - Dangerous Places!; Crime Prevention Services, Peel Regional Police, Brampton, Ontario

McKay, Tom; October, 1996; The Right Design for Reducing Crime; Crime Prevention Through Environmental Design, Case Studies; Peel Regional Police, Brampton, Ontario;

Morani, Cynthia D., Esq.; Urschalitz, Paul E.; January 1993; Security by Design, Inc., Neighborhoods and Environmental Security; Quality Cities

National Crime Prevention Centre; 1998; Safety and Savings: Crime Prevention Through Social Development; Department of Justice, Canada

National Crime Prevention Council, (2003) "Crime prevention through environmental design Guide Book.

NCSCR National Center for social and criminological research. http://www.ncscr.org.eg/main.php.

Newman, O. (1972). Defensible Space: People and design in the violent city. New York: Macmillan.

Newman, O. (1996). Creating defensible space. Washington, DC: U.S. Department of Housing and Urban Development.

Perry, C.A. (1929a) "The Neighborhood Unit: A scheme of arrangement for the Family Life Community." In A Regional Plan for New York and Its Environs, Volume vii. New York: 1929.

Putnam, Robert (1995) "Bowling Alone: America's Declining Social Capital" Journal of Democracy 6(1)

Putnam, Robert (2000) Bowling Alone: The Collapse and Revival of American Community (New York: Simon and Schuster).

Sampson, Robert J., Stephen Raudenbush, and Felton Earls. 1997. "Neighborhoods and Violent Crime: A Multilevel Study of Collective Efficacy." Science 277:918- 24.

Silver, C (1985), "Neighborhood Planning in Historical Perspective," Journal of the American Planning Association. 51:2, 161-174 
Solow A., Ham C., and Donnelly E. (1969) "The Concept of The Neighborhood Unit: Its emergence and Influence on Residential Environmental Planning and Development." Graduate School of Public and International Affairs, University of Pittsburgh, 1969: 73-75

Susan Geason and Paul R. Wilson (1946)" Designing out crime: Crime prevention through environmental design" Australian Institute of Criminology.

Tanaka, H., Chen, Y., Zhao, H., and Shibasaki, R. (2007) Quantification of Natural Surveillance in Urban Areas for Crime Prevention Using Vehicleborne Laser,

Tennant, Melanie D.; 1998; Building To Reduce Crime - Guidelines For Crime Prevention Through Environmental Design, Development Services Department, City of North Vancouver, B.C.

Vogel, M. and Pettinari, J. (2002). Personal safety and transit: Paths, environments, stops and stations: Final Report. Minneapolis, MN: Centre for Transportation Studies. 